\title{
Peran Karakteristik Individu Sebagai Salah Satu Penentu Peningkatan Kinerja Karyawan
}

\author{
Devi Ika Agustina ${ }^{1}$, Aprih Santoso ${ }^{2}$
}

1,2Fakultas Ekonomi Universitas Semarang

\begin{tabular}{|c|c|}
\hline INFO ARTIKEL & Abstract \\
\hline \multirow[t]{2}{*}{$\begin{array}{l}\text { Keywords: } \\
\text { individual, commitment, } \\
\text { motivation, superoision }\end{array}$} & $\begin{array}{l}\text { This research is motivated by a decrease in targets and realization in } 2019 \text { at PT. } \\
\text { Bitratex Industries Semarang. The purpose of this research is to analyze the } \\
\text { factors that influence employee performance. Samples were taken by purposive } \\
\text { sampling technique. Analysis tool with multiple linear regression, hypothesis } \\
\text { testing ( } t \text {, F and coefficient of determination) and model accuracy test. The results } \\
\text { showed that there was a positive and significant effect of individual } \\
\text { characteristics, organizational commitment, intrinsic motivation and supervision } \\
\text { where the better the employee's performance will increase. For the work } \\
\text { environment is well formed then it has no effect on employee performance. The } \\
\text { value of the coefficient of determination of } 0.616 \text { means that individual } \\
\text { characteristics, organizational commitment, intrinsic motivation, supervision and } \\
\text { work environment can affect employee performance by } 61.6 \% \text { and the remaining } \\
38.4 \% \text { is influenced by other variables. }\end{array}$ \\
\hline & Abstraks \\
\hline $\begin{array}{l}\text { Kata Kunci: } \\
\text { individu, } \\
\text { motivasi, } \\
\text { lingkungan } \\
\text { DOI: }\end{array}$ & $\begin{array}{l}\text { Penelitian ini dilatar belakangi adanya penurunan target dan realisasi } \\
\text { pada tahun } 2019 \text { di PT. Bitratex Industries Semarang. Tujuan penelitian } \\
\text { adalah menganalisis faktor yang mempengaruhi kinerja karyawan. } \\
\text { Sampel diambil dengan teknik purposive sampling. Alat analisis dengan } \\
\text { regresi linier berganda, uji hipotesis (t, F dan koefisien determinasi) dan } \\
\text { uji ketepatan model. Hasil penelitian menunjukkan ada pengaruh positif } \\
\text { dan signifikan dari karakteristik individu,komitmen organisasi, motivasi } \\
\text { instrinsik dan pengawasan dimana semakin baik maka kinerja karyawan } \\
\text { akan mengalami peningkatan, Untuk lingkungan kerja sudah terbentuk } \\
\text { dengan baik maka tidak berpengaruh terhadap kinerja karyawan. Nilai } \\
\text { koefisien determinasi } 0,616 \text { artinya karakteristik individu, komitmen } \\
\text { organisasi, motivasi instrinsik, pengawasan dan lingkungan kerja mampu } \\
\text { mempengaruhi kinerja karyawan sebesar } 61,6 \% \text { dan sisanya } 38,4 \% \\
\text { dipengaruhi oleh variabel lain. }\end{array}$ \\
\hline \multicolumn{2}{|l|}{$\begin{array}{l}\text { Koresponsi: } \\
\text { Nama: Aprih Santoso } \\
\text { Email: aprihsantoso@usm.ac.id }\end{array}$} \\
\hline $\begin{array}{l}\text { PENDAHULUAN } \\
\text { Semua individu bekerja } \\
\text { ebut Sumber Daya Manus } \\
\text { Peran SDM sangat penting } \\
\text { hingga patut ditangai secar }\end{array}$ & $\begin{array}{l}\text { akan terwujud dalam bentuk kinerja. Kinerja ada- } \\
\text { lah prestasi kerja untuk mencapai tujuan } \\
\text { organisasi, memuaskan konsumen dan } \\
\text { berkonstribusi bagi perekonomian. Pada dasarnya } \\
\text { kinerja merefleksikan sejauh mana kegiatan } \\
\text { individu dalam menjalankan tugas untuk mencapai }\end{array}$ \\
\hline
\end{tabular}




\section{Peran Karakteristik Individu Sebagai Salah Satu Penentu \\ Peningkatan Kinerja Karyawan \\ Devi Ika Agustina, Aprih Santoso}

tujuan organisasi. Baik buruknya kinerja karyawan akan menguntungkan atau justru mendapatkan kerugian untuk perusahaan. Disisi lain, Kinerja buruk berakibat semangat kerja karyawanakan turun yang akan berdampak pada target yang tidak terercapai sesuai ketentuan perusahaan.

Salah satu faktor yang mempengaruhi kinerja karyawan adalah karakteristik individu. Konstribusi kinerja karyawan untuk perusahaan akanberbeda manakala karakteristik individunya berbeda-beda. Karakteristik individu mencakup usia, jenis kelamin, tingkat pendidikan, status perkawinan, dan masa kerja dalam organisasi (Robbins, 2016). Dessy, dkk. 92018) dan Laoh, dkk (2019) menyebutkan kinerja karyawan di pengaruhi karateristik individu.

Komitmen organisasi juga berperan penting dalam menciptakan kinerja karyawan. Keterikatan dan mengenalnya seorang karyawan atas organisasinya merupakan sikap sebagai komitmen terhadap organisasinya. Hasil penelitian Putra (2015) danRahayu (2017) menyebutkan bahwa kinerja karyawan dipengaruhi oleh komitmen organisasi. Motivasi instrinsik merupakan motivasi terkuat sebab ada pada diri seorang karyawan. Kesadaran akan menimbulkan kinerja yang bagus karena di anggap dapat mencukupi keperluan kehidupan sehari-harinya. Penelitian dari Prahiawan \& Simbolon (2014) dan Safitri \& Susanto (2019) menemukan bahwa motivasi instrinsik mempunyai pengaruh signifikan terhadap kinerja karyawan.

Di dalam suatu organisasi, mutlak harus dilakukan pengawasan karena sebagai alat kendali baik buruknya jalan organisasi tersebut. Jika organisasi tanpa adanya pegawasan maka lambat maupun cepat menyebakan bangkrutnya suatu organisasi. Penelitian dari Herdino \&Andri (2017) dan Joko, dkk. (2019) menyatakan pengawasan berpengaruh positif terhadap kinerja karyawan.

Lingkungan kerja perlu diperhatikan agar karyawan dapat semakin meningkatkan kemampuan dan semangat kerja sehingga dapat menghasilkan kinerja yang baik. Lingkungan kerja yang sesuai keinginan karyawan akan menciptakan kinerja semakin baik. Penelitian dari Prahiawan \& Simbolon (2014), Dessy, dkk. (2018) dan Chasanah, dkk (2020) bahwa lingkungan kerja kerja berpengaruh terhadap kinerja karyawan. Namun, lingkungan kerja tidak memiliki pengaruh terhadap kinerja karyawan, apabila lingkungan buruk maka kinerja buruk (Effendy \& Fitria, dkk, 2019).
Berdasarkan data produksi bagian backprocess PT. Bitratex Industries Semarang, jumlah produksi barang tidak sesuai target dan realisasi, adalah:

Tabel 1.Produksi Bagian BackProcess PT. Bitratex Industries Semarang

\begin{tabular}{lllll}
\hline Bulan & Target & Realisasi & Persen & Keterangan \\
\hline Januari & 472.500 & 458.617 & 97,06 & \\
Februari & 472.500 & 449.031 & 95,03 & $-2,03$ \\
Maret & 472.500 & 452.792 & 95,83 & 0,80 \\
April & 472.500 & 458.335 & 97,00 & 1,17 \\
Mei & 472.500 & 468.429 & 99,14 & 2,14 \\
Juni & 472.500 & 426.902 & 90,35 & $-8,79$ \\
Juli & 472.500 & 428.006 & 90,58 & 0,23 \\
Agustus & 472.500 & 469.471 & 99,36 & 8,78 \\
September & 472.500 & 455.993 & 96,51 & $-2,85$ \\
Oktober & 472.500 & 458.257 & 96,99 & 0,48 \\
Nopember & 472.500 & 460.462 & 97,45 & 0,47 \\
Desember & 472.500 & 478.359 & 101,24 & 3,79 \\
\hline
\end{tabular}

Tabel 1 menunjukkan adanya masalah dengan kinerja karyawan produk yaitu tidak tercapainya target. Tujuan penelitian untuk menganalisis pengaruh karakteristik individu, komitmen organisasi, motivasi instriksik, pengawasan dan lingkungan kerja terhadap kinerja karyawan.

\section{TELAAH PUSTAKA DAN PERUMUSAN HIPOTESIS \\ Karakteristik Individu}

Robbins (2016), agar karyawan dapat melakukan kerja dengan baik, maka perlunya kesesuaian dengan kerja karyawan sehingga akan didapatkan kecocokkan sifat karyawan terhadap kemampuannya, yang pada akhirnya ada peningkatan kinerja karyawan. Gibson,dkk. (2013), variabel yang melekat pada individu dapat dikelompokkan,menjadi: a. Baik fisik maupun mental atas kemampuan dan ketrampilan karyawan. b. Demografis. c. Latar belakang keluarga, tingkat sosial dan pengalaman serta variabel psikologis individu yang meliputi persepsi, sikap dan kepribadian, belajar, dan motivasi. Proses psikologi seseorang untuk mendapatkan, mengkonsumsi, menerima barang/jasa dan pengalaman adalah suatu karaktkeritik individu (Huriyati, 2011). Dessy, dkk. (2018) dan Laoh, dkk (2019) menyebutkan kinerja karyawan dipengaruhi secara positif dan signifikan oleh karateristik individu.

\section{Komitmen Organisasi}

Refleksi loyalitas seorang karyawan untuk organisasi secara berkelanjutan dengan cara mengekspresikan perhatiaanya terhadap organisasi 
demi perkembangan organisasinya sevara terus menerus merupakan suatu bentuk komitmen organisasi. Keberpihakan karyawan pada organisasi yang sesuai dengan keinginannya agat tetap bertahan dalam organisasi tersebut disebut komitmen organisasi (Robbins, 2016). Ada tiga dimensi komitmen organisasi, yaitu affective commitment, continuance commitment dan normative commitment. Hasil penelitian Putra (2015) dan Rahayu (2017) menyatakan komitmen organisasi berpengaruh terhadap kinerja karyawan.

\section{Motivasi Instrinsik}

Motivasi berperan penting dalam penciptaan kinerja. Munculnya motivasi dari addanya dorongan dasar atau keinginan seorang karyawan guna mencurahkan kemampuannya untuk mewujudkaj tujuan. Tujuan tersebut bisa merupakan soal keperluan hidup sehingga akan muncul suatu motivasi tapi jika tidak kebutuhan maka niscaya muncul motivasi teersebut. Prahiawan \& Simbolon (2014) dan Safitri \& Susanto (2019) menemukan bahwa motivasi instrinik mempunyai pengaruh signifikan terhadap kinerja karyawan.

\section{Pengawasan}

Untuk meningkaktan kinerja yang baik butuh adanya pengawasan sehingga pengawasan memegang peranan penting dalam suatu organisasi. Tujuan adanya pengawasan adalah untuk mengaplikasikan antara standar pelaksanaan terhadap tujuan perencanaan, membuat sistem informasi feedback, mengkomparasikan kegiatan riil dan standarnya, menetapkan dan mengevaluasi nya, lalu melakukan perbaikan-perbaikan gunamemastikan atas penggunaan sumber daya organisasi dalam rangka terwujudnya tujuan organisasi. Hasil penelitian Herdino \& Andri (2017) dan Joko, dkk. (2019) menyatakan bahwa pengawasan berpengaruh positif terhadap kinerja karyawan.

\section{Lingkungan Kerja}

Suatu kondisi kerja tertentu yang terkait dengan hubungan kerja dalam suatu organisasi disebut lingkungan kerja nonfisik (Sedarmayanti, 2001). Kewajiban organisasi untuk mendukung munculnya inisiatif dan kreativitas karyawan agar tercipta kondisi lingkungan kerja yang baik sangatlahdibutuhkan. Hasil penelitian Prahiawan \& Simbolon (2014),Dessy, dkk. (2018) dan Chasanah, dkk (2020) menyatakan kinerja karyawan dipengaruhi lingkungan kerja. Namun, kinerja karyawan justru tidak dipengaruhi oleh lingkungan kerja, jika lingkungan kerja buruk (Effendy\& Fitria, 2019).

\section{Kinerja Karyawan}

Kinerja karyawan merupakan tingkat keberhasilan karyawan dalam melaksanakan tugas dan tanggung jawabnya. Kinerja karyawan mempengaruhi seberapa banyak karyawan konstribusi kepada organisasi. Kinerja karyawan akan dipengaruhi faktor internal dan faktor eksternal. Kinerja yang baik harus dipenuhi oleh seorang karyawan: Terdapat 5 tolak ukur untuk mengevaluasi kinerja karyawan, yaitu : tanggung jawab, kuantitas kerja, inisiatif, ketaatan, kualitas kerja dan kerjasama (Mangkunegara, 2000)

Hubungan Logis Antar Variabel dan Perumusan Hipotesis

Pengaruh Karakteristik Individu Terhadap Kinerja Karyawan.

Faktor seorang individu yang memiliki sifat khas sesuai dengan perwatakan tertentu atau cara memandang ke objek tertentu dan coba menafsirkan apa yang dilihatnya disebut karakteristik individu. Hasil penelitian Dessy, dkk. (2018) dan Laoh, dkk (2019) menunjukkan bahwa karakteristik individu berpengaruh positif dan signifikan terhadap kinerja karyawan artinya setiap perubahan kinerja karyawan dipengaruhi oleh karakteristik individu.

H1: Karakteristik Individu berpengaruh terhadap Kinerja Karyawan.

Pengaruh Komitmen Organisasi terhadap Kinerja Karyawan.

Dimensi perilaku utama bagi karyawan agar bisa dipakai menilai kecenderungannya betah lama di organisasi disebut komitmen organisasi. Tingginya komitmen karyawanakan berdampak pada menyatunya dirinya dengan perusahaan. Oleh karena itu, karyawan merasa memiliki atas keberlangsungan hidup perusahaannya. Hasil penelitian Putra (2015) dan Rahayu (2017) menyatakan bahwa kinerja karyawan dipengaruhi komitmen organisasi.

H2: Komitmen Organisasi berpengaruh positif terhadap Kinerja Karyawan.

\section{Pengaruh Motivasi Instrinsik terhadap Kinerja Karyawan.}

Suwarno (2001) menyatakan motivasi instrinsik adalah motif-motif yang menjadi berfungsi atau aktif tidak membutuhkan rangsangan dari luar, sebab sudah adanya dorongan melaksanakan sesuatu di dalam diri seseorang tersebut. Atas dasar kesadaran sendiri dari karyawan justru akan menimbulkan kinerja karyawan optimal. Selanjutnya karyawan akan dapat teerpenuhi keperluan hidup sehari-harinya. Penelitian Prahiawan \& Simbolon (2014) dan Safitri \& Susanto (2019) 


\section{Peran Karakteristik Individu Sebagai Salah Satu Penentu \\ Peningkatan Kinerja Karyawan \\ Devi Ika Agustina, Aprih Santoso}

menemukan bahwa motivasi instrinik mempunyai pengaruh signifikan terhadap kinerja karyawan.

H3: Motivasi Instrinsik berpengaruh signifikan terhadap Kinerja Karyawan.

\section{Pengaruh Pengawasan terhadap Kinerja Karyawan.}

Pelaksanaan suatu rencana dan program tanpa diiringi dengan suatu sistem pengawasan yang intensif dan berkesinambungan jelas akan mengakibatkan lembatnya, atau bahkan tidak tercapainya sasaran dan tujuan yang telah ditentukan. Jadi pengawasan penting untuk dilaksanakan, mengingat Pengawasan akan berpengaruh pada keberlangsungan perusahaan dan dapat mendeteksi atas dilaksanakannya tugas tertentu apakah telah sama dengan perintah, tujuan dan kebijakan serta rencananya dalam rangka pencapaian tujuan organisasinya.Hasil penelitian Herdino \& Andri (2017) dan Joko, dkk. (2019) menyatakan pengawasan berpengaruh positif dan signifikan terhadap kinerja karyawan.

H3: Pengawasan berpengaruh positif dan signifikanterhadap Kinerja Karyawan.

\section{Pengaruh Lingkungan Kerja terhadap Kinerja} Karyawan.

Suatu kondisi yang ada terkait dengan relasi kerja dalam organisasi disebut lingkungan kerja. Komunikasi yang baik, pengendalian diri dan suasana kekeluargaanlah yang dibutuhkan agar kondisi lingkungan kerja lebih baik (Sedarmayanti (2001). Dengan kinerja karyawan yang baik maka akan muncul lingkungan kerja yang kondusif. Prahiawan \& Simbolon (2014), Dessy, dkk. (2018), dan Chasanah, dkk (2020) bahwa lingkungan kerja kerja berpengaruh terhadap kinerja karyawan.

H5: Pengaruh Lingkungan Kerja tidak berpengaruh terhadap Kinerja Karyawan.

\section{METODE}

\section{Populasi dan Sampel}

Populasi yang digunakan seluruh karyawan produksi bagian backprocess PT. Bitratex Indutries Semarang berjumlah 270 karyawan. Dengan menggunakan rumus Slovin diperoleh sampel 73 orang, dengan kriterianya : karyawan yang telah bekerja minimal 3 tahun dan usia minimal 27 tahun.

\section{Uji Instrumen}

Dalam penelitian ini menggunakan Uji Validitas, Uji Reliabilitas, Uji Asumsi Klasik (Uji Normalitas, Uji Multikolonieritas, Uji Heteroskedastisitas).

\section{Regresi Linier Berganda}

Persamaan linier regresi berganda dapat dilihat dengan rumus :

$$
\mathrm{KK}=\mathrm{b} 1 \mathrm{KI}+\mathrm{b} 2 \mathrm{KO}+\mathrm{b} 3 \mathrm{MI}+\mathrm{b} 4 \mathrm{P}+\mathrm{b} 5 \mathrm{LK}+\mathrm{e}
$$

Keterangan :

$\begin{array}{ll}\text { KK } & : \text { Kinerja karyawan } \\ \boldsymbol{\beta}_{\mathbf{1}}-\boldsymbol{\beta}_{\mathbf{5}} & \text { : Koefisien Regresi } \\ \text { KI } & \text { : Karakteristik Individu } \\ \text { KO } & \text { : Komitmen Organisasi } \\ \text { MI } & \text { : Motivasi Instrinsik } \\ \text { P } & \text { : Pengawasan } \\ \text { LK } & \text { : Lingkungan Kerja } \\ \boldsymbol{e} & \text { : erorr or term }\end{array}$

\section{Uji Signifikansi}

Dalam penelitian ini menggunakan uji statistik $t$ dan uji statistik F.

\section{Koefisien Determinasi $\left(\mathbf{R}^{2}\right)$}

Dalam penelitian ini menggunakanuji Koefisien determinasi $\left(\mathrm{R}^{2}\right)$ dengan hasil antara nol dan satu. $\left(\mathrm{R}^{2}\right)$.

\section{RESULT AND DISCUSSION \\ Uji Validitas}

Koefisien kritis diperoleh dari tabel distribusi $r$ dengan menggunakan derajat bebas $\mathrm{df}=\mathrm{n}-2=73-2$ $=71$ dengan taraf signifikan sebesar $5 \%$ yaitu $r$ tabel $=0,2441$. Hasil analisis ternyata semua indikator yang digunakan untuk mengukur variabel-variabel yang digunakan dalam penelitian ini mempunyai $r$ hitung bergerak dari 0,332 sampai dengan 0,939 > r table $=0,2303$ (nilai $r$ tabel untuk $n=73$ ). Sehingga semua indikator tersebut adalah valid.

\section{Uji Reliabilitas}

Uji reliabilitas pada pengujian ini menggunakan Cronbach Alpha $(\alpha)$, dimana jika $\alpha>0,60$ maka kuesioner dikatakan konsisten atau reliabel. Hasil uji reliabilitas menunjukkan bahwa semua variabel mempunyai koefisien Alpha yang bergerak dari 0,609 sampai dengan 0,895 > 0,60 sehingga semua konsep pengukur masing-masing variabel dari kuesioner adalah reliabel sehinggaitem pada masing-masing konsep variabel tersebut layak digunakan sebagai alat ukur. 


\section{Uji Normalitas}

Tabel 2. Hasil Uji Normalitas

One-Sample Kolmogorov-Smirnov Test

\begin{tabular}{llc}
\hline & & \multicolumn{2}{c}{$\begin{array}{c}\text { Unstandardized } \\
\text { Residual }\end{array}$} \\
\hline $\mathrm{N} \quad$ Normal Parameters \\
& Mean & 73 \\
& Std. Deviation &, 0000000 \\
Most Extreme & Absolute & 1,11542050 \\
Differences & Positive &, 101 \\
& Negative &, 101 \\
Test Statistic & &,- 058 \\
Asymp. Sig. (2-tailed) & &, 101 \\
\hline
\end{tabular}

Hasil data terlihat, bahwa data terdistribusi dengan normal.Hal ini dilihat dari nilai Asymp. Sig sebesar 0,061 >0,05 berarti data variabel telah terdistribusi dengan normal secara statistik.

\section{Uji Multikolinieritas}

Tabel 3. Hasil Uji Multikolinieritas

\begin{tabular}{llcc}
\hline & \multicolumn{2}{c}{ Collinearity } & Statistics \\
Model & Tolerance & VIF \\
\hline $1 \quad$ (Constant) & & \\
& Karakteristik Individu &, 692 & 1,446 \\
& Komitmen Organisasi &, 864 & 1,158 \\
& Motivasi Instrinsik &, 744 & 1,344 \\
& Pengawasan &, 574 & 1,743 \\
& Lingkungan Kerja &, 913 & 1,096 \\
\hline
\end{tabular}

Hasil pengujian menunjukkan bahwa nilai VIF dari semua variabel bebas memiliki nilai yang bergerak dari 1,096 sampai dengan 1,743 < 10 dan nilai tolerance bergerak dari 0,574 smpai dengan $0,913>0,10$ berarti semua variabel tidak menunjukkan adanya gejala multikolinieritas dalam model regresi.

\begin{tabular}{lll}
\multicolumn{2}{c}{ Tabel 4. Hasil Uji Glejser } \\
\hline \multicolumn{1}{l}{ Model } & Sig \\
\hline $1 \quad$ (Constant) &, 879 \\
& Karakteristik Individu &, 155 \\
& Komitmen Organisasi &, 528 \\
& Motivasi Instrinsik &, 253 \\
& Pengawasan &, 160 \\
& Lingkungan Kerja &, 260 \\
\hline
\end{tabular}

Dari uji Glejser bahwa nilai signifikansi bergerark dari lebih 0,160 sampai dengan 0,879 > 0,05 berarti tidak terjadi heterokedastisitas pada model regresi, sehingga model regresi layak untuk digunakan dalam melakukan pengujian.

\section{Hasil Regresi Linear Berganda}

Tabel 5.Hasil Uji Regresi Linear berganda

\begin{tabular}{lclll}
\hline Model & $\begin{array}{c}\text { Standardized } \\
\text { Coefficients }\end{array}$ & T & Sig. \\
\hline
\end{tabular}

\begin{tabular}{lccc}
\cline { 2 - 2 } & \multicolumn{2}{c}{ Beta } & \\
\hline J(Constant) & & 2,074 &, 042 \\
Karakteristik Individu &,- 000124 &,- 001 &, 999 \\
Komitmen Organisasi &, 168 & 2,054 &, 044 \\
Motivasi Instrinsik &, 232 & 2,635 &, 010 \\
Pengawasan &,- 382 & $-3,808$ &, 000 \\
Lingkungan Kerja &, 710 & 8,938 &, 000
\end{tabular}

Berdasarkan tabel diatas, maka persamaan regresi linear adalah :

$Y=-0,000124 X 1+0,168 X 2+0,232 X 3-$ $0,382 X 4+0,710 \times 5+\mathrm{e}$

Persamaan regresi memiliki arti sebagai berikut:

1. Nilai koefisien beta pada variabel karakteristik individu menunjukkan angka sebesar $-0,000124$ artinya apabila karakteristik individu ditingkatkan, maka kinerja karyawan akan mengalami penurunan.

2. Nilai koefisien beta pada variabel komitmen organisasi menunjukkan angka sebesar 0,168 artinya apabila komitmen organisasi semakin baik maka kinerja karyawan akan meningkat.

3. Nilai koefisien beta pada variabel motivasi instrinsik menunjukkan angka sebesar 0,232 artinya kinerja karyawan akan meningkat.bila motivasi instrinsik ditingkatkan.

4. Nilai koefisien beta pada variabel pengawasan menunjukkan angka sebesar -0,382 artinya apabila pengawasan meningkat maka kinerja karyawan akan mengalami penurunan.

5. Nilai koefisien beta pada variabel lingkungan kerja menunjukkan angka sebesar 0,710 artinya kinerja karyawan akan meningkat. Jika lingkungan kerja semakin baik.

\section{Uji Hipotesis}

a. Karakteristik Individu (H1)

Didapatkan hasil $t_{\text {hitung }}=-0,001<t_{\text {tabel }}=1,993$, tingkat sig 0,999>0,05 sehingga Hotidak ditolak maknanya karakteristik individu tidak mempengaruhi secara signifikan pada kinerja karyawan. Untuk pernyataan H1 Ditolak karena meskipun memiliki usia, pendidikan, status, pengalaman kerja, dan jenis kelamin yang berbeda-beda namun karyawan melakukan pekerjaan sesuai dengan karyawan lain. Apabila karyawan melakukan pekerjaan dengan baik, maka karyawan yang lain juga melakukannya dengan baik tanpa ragu memandang karakteristik individu tiap karyawan. 


\section{Peran Karakteristik Individu Sebagai Salah Satu Penentu \\ Peningkatan Kinerja Karyawan \\ Devi Ika Agustina, Aprih Santoso}

Hasil ini tidak sesuai dengan teori yang mengatakan faktor karakteristik individu berpengaruh terhadap kinerja karyawan. Hasil penelitian ini bertentangan atau tidak sejalan dengan penelitian Dessy, dkk. (2018) dan Laoh, dkk (2019) yang menyebutkan karateristik individu justru berpengaruh positif dan signifikan terhadap kinerja karyawan.

Meskipun karyawan pada PT. Bitratex Industries Semarang memiliki latar belakang, usia, status, pengalaman dan gender yang berbeda-beda. Karyawan lebih mengerjakan pekerjaannya mengikuti karyawan yang lain. Apabila kebanyakan karyawan melakukan pekerjaan dengan cepat, maka sisanya juga akan bekerja dengan cepat. Begitu pula sebaliknya. Apabila kebanyakan karyawan melakukan pekerjaan dengan lambat. Maka karyawan yang lain melakukannya dengan lambat.

\section{b. Komitmen Organisasi}

Didapatkan hasil $t_{\text {hitung }}=2,054>\quad t_{\text {tabel }}=$ 1,993dengan sig 0,044<0,05 maka Ho ditolak berarti komitmen organisasi berpengaruh signifikan terhadap kinerja karyawan.Untuk pernyataan $\mathrm{H} 2$ diterima. Hasil ini sesuai dengan teori yang mengatakan faktor komitmen organisasi berpengaruh terhadap kinerja karyawan. Hasil penelitian Putra (2015) dan Rahayu (2017) menyatakan kinerja karyawan dipengaruhi komitmen organisasi.

Diperlukan komitmen dari berbagai pihak didalam perusahaan agar tujuan perusahaan tercapai dengan optimal, termasuk komitmen karyawan PT. Bitratex Industries Semarang. Perusahaan akan memberi perhatian yang banyak kepada karyawan supaya loyal sehinggga muncul komitmen karyawan secara maksimal. Alhasil, perusahaan akan memiliki karyawan yang loyaldemi memenuhi kebutuhan perusahaan tersebut..

\section{c. Motivasi instrinsik}

Didapatkan hasil $t_{\text {hitung }}=2,635>t_{\text {tabel }}=1,993$ dengan sig 0,010<0,05 maka Ho ditolak berarti motivasi instrinsik berpengaruh signifikan terhadap kinerja karyawan. Untuk pernyataan H3 Diterima. Hasil ini sesuai dengan teori yang mengatakan faktor motivasi instrinsik berpengaruh terhadap kinerja karyawan.

Hasil penelitian ini sejalan dengan penelitian yang dilakukan oleh hasil penelitian
Prahiawan \& Simbolon (2014) dan Safitri \& Susanto (2019) menemukan bahwa motivasi instrinik mempunyai pengaruh pada kinerja karyawan. Pengaruh ini karena motivasi instrinsik sudah ada pada diri seorang karyawan tersebut. Melalui motivasi instrinsik membuat karyawan PT. Bitratex Industries Semarang sadar akan tanggung jawab dan pekerjaanya lebih baik dan terdorong untuk semangat menyelesaikan dengan baik pekerjaanya.

\section{d. Pengawasan}

Didapatkan hasil $t_{\text {hitung }}=-3,808>t_{\text {tabel }}=1,993$, nilai sig 0,000 <0,05 sehingga $\mathrm{Ha}$ diterima maknanya pengawasan berdampak negatif dan signifikan terhadap kinerja karyawan. Alasannya pengawasan yang dilakukan sedikit atau tidak terlalu ketat, karyawan merasa nyaman dan melakukan pekerjaan dengan senang sehingga kinerjanya semakin meningkat. Sebaliknya pengawasan dilakukan dengan terlalu ketat maka karyawan akan merasa tertekan dan merasa tidak nyaman. Untuk pernyataan $\mathrm{H} 4$ Diterima.

Hasil ini tidak sesuai dengan teori yang mengatakan faktor pengawasan berpengaruh positif terhadap kinerja karyawan. Hasil penelitian ini tidak sejalan dengan penelitian yang dilakukan oleh hasil penelitian Herdino \&Andri (2017), Joko, dkk. (2019) menyatakan pengawasan berpengaruh positif terhadap kinerja karyawan.

Pelaksanaan pengawasan sangat mutlak dilakukan mengingat dapat berpengaruh pada kinerja suatu perusahaan. Pengawasan di setiap departemen berbeda-beda itulah yang memberikan sebagian karyawan PT. Bitratex Industries Semarang menjadi tertekan dalam melaksanakan kewajibannya. Perusahaan harus melakukan koreksi dan menerapkan pengawasan sesuai dengan rencana, perintah, tujuan, dan kebijakan dalam upaya mencapai tujuan yang telah ditetapkan.

\section{e. Lingkungan Kerja}

Didapatkan hasil $t_{\text {hitung }}=8,938>t_{\text {tabel }}=1,993$, nilai sig 0,000 <0,05 sehingga Ho tidak diterima maknanya kinerja karyawan dipengaruhi lingkungan kerja secara positif dan signifikan. Untuk pernyataan H5 diterima.Hasil ini mengatakan faktor lingkungan kerja berpengaruh terhadap kinerja karyawan.Hasil penelitian ini mendukung penelitian Prahiawan \& Simbolon (2014), Dessy, dkk. 
(2018) dan Chasanah, dkk (2020) bahwa lingkungan kerja berpengaruh terhadap kinerja karyawan. Namun, hasil penelitian ini tidak sejalan dengan penelitian yang dilakukan oleh Effendy dkk (2019), kinerja karyawan tidak dipengaruhi lingkungan kerja, Lingkungan kerja yang baik akan memberikan dampak baik untuk mencapai tujuan perusahaan.

Koefisien Determinasi ( $\left.\mathbf{R}^{2}\right)$

Tabel 6. Hasil Uji Koefisien Determinasi

\begin{tabular}{llllc}
\hline Model & R & R Square & \multicolumn{2}{c}{ Adjusted RStd. Error of } \\
Square & the Estimate \\
\hline $\mathbf{1}$ &, $783^{\mathrm{a}}$ &, 614 &, 585 & 1,15629 \\
\hline
\end{tabular}

a. Predictors: (Constant), x5, x3, x2, x1, x4

b. Dependent Variable: y

Pada tabel 5, nilai Adjusted $R^{2}$ sebesar 0,614 artinya $61,40 \%$ variasi dari kinerja karyawan dapat dijelaskan oleh variabel karakteristik individu, komitmen organisasi, motivasi instrinsik, pengawasan dan lingkungan kerja, sedangkan sisanya sebesar 38,60 \% dijelaskan oleh variabel lainnya.

\section{Uji F}

Tabel 7. Hasil Uji F ANOVA $^{a}$

\begin{tabular}{|c|c|c|c|c|c|c|}
\hline Model & & $\begin{array}{l}\text { Sum of } \\
\text { Squares }\end{array}$ & df & $\begin{array}{l}\text { Mean } \\
\text { Square }\end{array}$ & $\mathrm{F}$ & Sig. \\
\hline \multirow[t]{3}{*}{1} & Regression & 142,311 & 5 & 28,462 & 21,288 &, $000^{\mathrm{b}}$ \\
\hline & Residual & 89,580 & 67 & 1,337 & & \\
\hline & Total & 231,890 & 72 & & & \\
\hline
\end{tabular}

a. Dependent Variable: y

b. Predictors: (Constant), x5, x3, x2, x1, x4

Tabel 6 diperoleh nilai $F$ sebesar 21,288 dengan tingkat signifikansi $0,000<0,05$ berarti model regresi yang digunakan dapat memprediksi variabel dependen.

\section{KESIMPULAN}

Karakteristik individu, komitmen organisasi, motivasi instrinsik pengawasan dan lingkungan kerja memiliki pengaruh positif dan signifikan terhadap kinerja karyawan. Lingkungan kerja yang lebih baik akan membuat kinerja karyawan meningkat.

\section{SARAN}

Hasil dari analisis deskriptif terhadap jawaban responden mengenai karakteristik individu, indikator ketiga (pendidikan) mendapatkan frekuensi terendah, ini membuktikan pendidikan formal belum memberikan efek bagi perusahaan terutama bagian backrocesssehingga perusahaan dapat melakukan evaluasi setiap bulan guna meningkatkan kinerja karyawan lebih baik lagi dan target perusahaan bisa tercapai.

Hasil dari analisis deskriptif terhadap jawaban responden mengenai komitmen organisasi, indikator ketiga (peduli) mendapatkan frekuensi terendah, Disarankan perusahaan haus lebih memperhatikan karyawan dengan cara mengevaluasi untuk meningkatkan kepedulian sehingga dapat meningkatkan kinerja karyawan lebih baik lagi.

Hasil dari analisis deskriptif terhadap jawaban responden mengenai motivasi instrinsik indikator ketiga (pekerjaan) dan indikator keempat (peluang) mendapatkan nilai sama, mendapatkan frekuensi terendah. Ini menunjukkan responden belum memahami pekerjaan dan peluang adalah indikator berpengaruh untuk memotivasi diri sendiri. Tidak semua orang bisa bekerja dan mendapatkan peluang untuk bekerja di PT. Bitratex Industries Semarang, disarankan karyawan lebih memotivasi diri untuk mencapai target dan realisasi perusahaan lebih baik lagi.

Hasil dari analisis deskriptif terhadap jawaban responden mengenai pengawasan, indikator ke empat (kedisiplinan) medapatkan frekuensi terendah. Ini menunjukkan masih ada sebagian karyawan kurang patuh terhadap peraturan perusahaan. Disarankan perusahaan lebih memperhatikan kedisiplinan karyawan, contohnya kehadiran karyawan diharapkan masuk departemen 10 menit sebelum jam kerja, dimaksudkan agar karyawan lebih siap dalam menjalankan tugas dan kewajiban sebagai karyawan.

Hasil dari analisis deskriptif terhadap jawaban responden mengenai lingkungan kerja, indikator pertama (suara) mendapatkan frekuensi terendah. Ini menunjukkan masih ada sebagian karyawan menilai suara yang ditimbulkan oleh beroperasinya mesin sangat mengganggu. Disarankan perusahaan melakukan evaluasi apakah batas suara yang ditimbulkan sesuai batas pendengaran normal, maka karyawan harus mematuhi dan menggunkan alat pelindung berupa earplug entuk meminimalkan suara yang ditimbulkan oleh beroperasinya mesin. Sehingga suara yang ditimbulkan tidak mengganggu dan karyawan bisa fokus dalam menjalankan tugas dengan lebih baik lagi.

\section{Keterbatasan Penelitian}

Keterbatasan penelitian ini yaitu nilai $\mathrm{R}^{2}$ pada model regresi diperoleh 61,40 \% artinya karakteristik individu, komitmen organisasi, motivasi instrinsik, pengawasan dan lingkungan kerja secra bersama-ssama berpengaruh terhadap 


\section{Peran Karakteristik Individu Sebagai Salah Satu Penentu \\ Peningkatan Kinerja Karyawan \\ Devi Ika Agustina, Aprih Santoso}

kineerja karyawan, dan sisanya sebesar 38,60 \% dijelaskan oleh faktor-faktor lainnya.

\section{Agenda Penelitian yang Akan Datang}

Peneliti selanjutnya sebaiknya menambahkan atau mengganti variabel lain yang dapat mempengaruhi kinerja karyawan selain karakteristik individu, komitmen organisasi, motivasi instrinsik, pengawasan dan lingkungan kerja.

\section{DAFTAR PUSTAKA}

Chasanah, N.U. \&Nurhajati, Pardiman. 2020. Pengaruh Lingkungan Kerja, Kesehatan Kerja dan Keselamatan Kerja Terhadap Kinerja Karyawan pada Perusahaan Daerah Air Minum Kota Malang. e - Jurnal Riset Manajemen PRODI MANAJEMEN. 9 (11) : 2438.

http:/ / riset.unisma.ac.id/index.php/jrm/arti cle/view/6335

Dessy, Yunita, L., \&Sinulingga, NAB.. 2018. Pengaruh Karakteristik Individu dan Lingkungan Kerja Terhadap Kinerja Karyawan pada PT. Perkebunan Nusantara II Pagar Merbabu. Journal of Management Science (JMAS). 1 : 1 6https://exsys.iocspublisher.org/index.php/J MAS/article/view/1

Effendy, AA., \&Fitria, JR., 2019. Pengaruh Lingkungan Kerja dan Stress Kerja Terhadap Kinerja Karyawan (Studi Kasus PT. Modernland Realty, TBK). Jurnal Ilmiah Manajemen Forkamma. 2 (2) : 4961http:/ / openjournal.unpam.ac.id/index.php /FRKM/article/view/3406. DOI: 10.32493/frkm.v2i2.3406

Gibson, James, L; John. M. Ivancevich \&J.H. Donelly, 2013. Organisasi danManajemen, Perilaku, Struktur, Proses. Terj. Djoerban Wahid. Erlangga. Jakarta

Herdino, D. \& Andri, S. 2017. Pengaruh Pengawasan Terhadap Kinerja Karyawan pada PT. Holchim Indonesia Cabang Perawang Kabupaten Siak. Jom FISIP. 4 (2) : 111https://jom.unri.ac.id/index.php/JOMFSIP /article/view/16001

Huriyati. 2011. Bauran Pemasaran. Edisi 15. Alfabeta. Bandung.
Joko, T., Munir, R.\&Fattah, N., 2019. “Pengaruh Pengembangan Karier, Pengawasan dan Komitmen Pegawai Terhadap Kinerja Pegawai di Dinas Pengendalian Penduduk dan Keluarga Berencana Kabupaten Bantaeng." Journal of Management. 2 (2) : 1-16 https://journal.stieamkop.ac.id/index.php/y ume/article/view/392 Doi.org/10.2568/yum.v2i2.392

Laoh, J.,. Sendow, GM.\& Uhing, Y. 2019. "Pengaruh Karakteristik Individu dan Kompetensi Sumber Daya Manusia Terhadap Kinerja Karyawan pada Usaha Rumah Kopi di Manado." Jurnal EMBA. 7 (4) : 4620-4629 https:/ / ejournal.unsrat.ac.id/index.php/emb a/article/view/25283.

DOI: https://doi.org/10.35794/emba.v7i4.25283

Mangkunegara, AP. 2000. Manajemen Sumber Daya Manusia. PT. Remaja Rosdakarya. Bandung.

Prahiawan, W \&Simbolon, N.. 2014. Pengaruh Motivasi Instrinsik dan Lingkungan Kerja Terhadap Kinerja Karyawan pada PT. Intimas Lestari Nusantara. Jurnal Ekonomi. 5(1). 35-41 https://ejurnal.esaunggul.ac.id/index.php/E ko/article/view/1045.

Putra. S.W. 2015. Pengaruh Komitmen Organisasi, Budaya Organisasi, Gaya Kepemimpinan dan Lingkungan Terhadap Kinerja Karyawan pada Industri Kecil. Jurnal Ekonomi Modernisasi. 11 (1)

62-77. http://ejournal.unikama.ac.id/index.php/JEK O/article/view/869. DOI: https://doi.org/10.21067/jem.v11i1.869

Rahayu. ES. 2017. Pengaruh Komitmen Organisasi Terhadap Organizational Citizenship Behavior dan Kinerja Karyawan (Studi Kasus Karyawan Medik Rumah Sakit Fathma Medika Gresik. Jurnal Administrasi Bisnis (JAB). 52 (1) : 138-145. http://administrasibisnis.studentjournal.ub.ac .id/index.php/jab/article/view/2166

Robbins. 2016. Perilaku Organisasi. Edisi 15. Salemba Empat. Jakarta.

Safitri, A., Susanto. 2019. Pengaruh Motivasi Instrinsik, Motivasi Ekstrinsik, Kompetensi dan Komitmen Terhadap Kinerja Karyawan PT. Askrindo Semarang. Majalah Ilmiah 
Jurnal Studi Manajemen dan Bisnis Vol. 8 (1) 2021: 64-72

$\begin{array}{llll}\text { Solusi. } & 17 & \text { (3) } & \text { : }\end{array}$

DOI: http://dx.doi.org/10.26623/slsi.v17i3.16

33http://journals.usm.ac.id/index.php/solusi /article/view/1633. DOI: http:/ /dx.doi.org/10.26623/slsi.v17i3.1633

Sedarmayanti. 2001. Manajemen Perkantoran Modern. Bandar Maju. Bandung.

Suwarno. 2001. Asas-asas Manajemen Sumber Daya Manusia. Suci Press. Bandung 